\title{
Who will I be when I retire? The role of organizational commitment, group memberships and retirement transition framing on older worker's anticipated identity change in retirement
}

\author{
Daniel Jolles $^{1} \mathbb{D} \cdot$ Veronica M. Lamarche $^{1} \cdot$ Jonathan J. Rolison ${ }^{1} \cdot$ Marie Juanchich $^{1}$
}

Accepted: 2 February 2022

(c) The Author(s) 2022

\begin{abstract}
Retirement is an eagerly awaited life transition for many older workers, but some may anticipate their exit from the workforce will result in loss of meaningful work-based activities and social interactions. For older workers more committed to their organization, retirement might represent a threat to maintaining a consistent, positive identity. Across three pre-registered studies of US adults aged 49 to 75 , we investigated the relationship between organizational commitment and anticipated identity changes in retirement. Studies 1 and $2(N=1059)$ found that older workers largely anticipated positive changes to their identity in retirement. In Study 2, we divided older workers into two conditions and used a framing manipulation to present retirement as either a 'role exit' or a 'role entry'. In the 'role exit' condition, older workers less committed to their organization anticipated more positive changes when they held more group memberships compared to those with fewer group memberships. Those in the 'role entry' condition anticipated significantly more positive changes to their identity in retirement than those in the 'role exit' condition, but did not anticipate more positive changes based on organizational commitment or group memberships. More group memberships, but not lower organizational commitment, was associated with more positive anticipation of identity changes in retirement. Study $3(N=215)$ surveyed older adults after they had retired, finding that identity changes experienced post-retirement were less positive than those anticipated by older workers. We discuss the theoretical and applied implications of these findings for older workers' retirement decisions and wellbeing.
\end{abstract}

Keywords Aging workforce $\cdot$ Retirement $\cdot$ Identification $\cdot$ Work attitudes $\cdot$ Experimental design $\cdot$ Organizational commitment

\section{Introduction}

Retirement can be broadly defined as an individual's exit from the workforce occurring after middle age (Wang \& Shi, 2014), and while retirement can be an eagerly anticipated later life milestone (van Solinge \& Henkens, 2007), very little is known about how older workers expect themselves to change when they exit the workplace for the last time. Increasing recognition is being given to the potential for retirement from satisfying work to cause disruption to health and wellbeing (Kubicek et al., 2011; Wang, 2007; Wang \& Shi, 2014), including longer term declines in mental health

Daniel Jolles

daniel.jolles@essex.ac.uk

1 Department of Psychology, University of Essex, Wivenhoe Park Colchester, SL6 1ES Colchester, UK
(Dave et al., 2006; Heller-Sahlgren, 2017). Continuity theory of retirement suggests older adults are motivated to maintain a consistent, positive identity across time (Atchley, 1989; Feldman, 1994), and consistent identity is associated with a number of wellbeing outcomes, including greater selfesteem, and lower stress, anxiety and depression (Butzer \& Kuiper, 2006; Campbell et al., 2003). Important aspects of identity including physical appearance, attitudes, hobbies, material belongings and social relationships might all be subject to change upon leaving an organization and the workforce (James, 1890; Oyserman et al., 2012). These changes represent a potential disruption to identity continuity and subsequent wellbeing (Kim \& Moen, 2002; Zittoun et al., 2003). Better understanding of how older workers anticipate identity changes in retirement is important to understanding the potential disruption that might occur around retirement, as this anticipation is a likely factor in present-day decisions 
about career and post-work future (Reiff et al., 2020; Wilson $\&$ Gilbert, 2005).

How much older workers anticipate positive or negative changes to their identity in retirement might be expected to differ based on individual commitment towards the organization they work for as a source of personal meaning (McIntyre et al., 2014). The aim of this research is to expand on previous studies of retirement wellbeing by specifically examining if older workers' organizational commitment is associated with how positively (or negatively) they anticipate changes to their identity in retirement and the moderating role of social group memberships.

\section{Relationship between organizational commitment and anticipated identity change in retirement}

Life transitions can be periods of identity instability and change when commitment to the source of meaning is high prior to transition (Lodi-Smith \& Roberts, 2010; Slotter et al., 2010). For example, more committed romantic partners anticipate and experience greater identity instability in the period following a relationship breakup (Slotter et al., 2010). As working adults spend more than a third of their waking hours engaged in work, the organization they work for, including relationships with colleagues and daily work routines, also has the potential to become central to one's identity over time (Amiot et al., 2015). For example, among workers who experience job loss, those more committed to their organization experience greater disruption to their identity after the exit (McIntyre et al., 2014). Compared to younger workers, older workers are generally more committed to their organization (Bal et al., 2013; Ng \& Feldman, 2010). While this commitment can taper off after retirement age (Katz et al., 2019), prior to this it can be expected to influence older worker's anticipation of identity change upon leaving the organization.

Affective organizational commitment refers to peoples' emotional orientation and attachment to their organization (Allen \& Meyer, 1990), with older workers higher in commitment likely to see the organization as a key part of their identity. This commitment is associated with greater intention to continue working beyond retirement age (Jones \& McIntosh, 2010; Zhan et al., 2013), which suggests that older workers with more affective commitment towards their organization might view leaving it through retirement as a potential source of discontinuity (Atchley, 1989). This could be because older workers more committed to their organization have greater emotion towards it and can experience challenges regulating this emotion when faced with the work-based losses that retirement brings (Conroy \& O'Leary-Kelly, 2014). This leads more committed older workers to describe a more painful retirement transition experience, especially when they have few alternate activities outside their work (Barnes \& Parry, 2004).

\section{Relationship between social group memberships and anticipated identity change in retirement}

Although older workers high in affective organizational commitment may see their organization as a key part of their identity, work is just one of many varied social identities that people hold across the lifespan (Lodi-Smith et al., 2017). So, the identity disruption anticipated by older workers upon leaving an organization for retirement might depend not only on their commitment to the organization, but also their access to other social identities. A social identity approach suggests that in retirement other group memberships (e.g., volunteer, fitness groups) might support identity continuity by providing an alternative source of social support and meaning (Greenaway et al., 2016; Iyer et al., 2009; Tajfel \& Turner, 2001). The way we see ourselves is heavily influenced by how others see us, with social relationships and interactions being a critical source of self-knowledge (James, 1890; Markus \& Wurf, 1987). Organizations themselves can be an important group membership or social identity (e.g., 'academic at Harvard Business School', 'Microsoft employee'), as they provide a resource for connection, meaning and self-esteem (Haslam, Lam, et al., 2018; Haslam, McMahon, et al., 2018). A growing body of evidence links multiple group memberships with better wellbeing outcomes in retirement, including higher life satisfaction, and better retirement adjustment (Haslam et al., 2018; Haslam, McMahon, et al., 2018; Steffens et al., 2016). Group memberships can also make positive contributions to identity in retirement by increasing identification with other retirees (Haslam et al., 2018a, b) and providing opportunities to pursue new activities, learning and social connections (Mattingly \& Lewandowski, 2013; van Solinge \& Henkens, 2007). Thus, depending on the strength of organizational commitment, multiple group memberships and the alternative social identities they provide, could influence how older workers anticipate identity changes in retirement. Building on this, we expect that for older workers who are less committed to their organization and participate in a greater number of groups, retirement might be anticipated more positively than for those with greater commitment, as it presents the opportunity to increase investment in these alternative group identities without the loss associated with leaving the organization.

To better understand the connection between organizational commitment, group memberships and identity changes in retirement, it is important to consider how positively people feel about themselves and the sociodemographic attributes that might influence their anticipation 
of retirement. Attitudes towards the self, including identity change, self-efficacy and beliefs about one's future success are often explained by self-esteem (DeMarree \& Bobrowski, 2017; Marsh et al., 2019), the extent to which one's identity is viewed as more positive and worthwhile (Rosenberg, 1965). As higher self-esteem is also associated with greater organizational commitment (Chang et al., 2012) and more group memberships (Jetten et al., 2015), it might help to explain how positively older workers anticipate changes to their identity in retirement. Similarly, a number of demographic factors can shape people's working lives and have significant influence over their retirement wellbeing including, education (e.g.,Wang \& Shi, 2014), financial position (e.g., Bonsang \& Klein, 2012), gender (e.g., Kim \& Moen, 2002) and years from retirement (e.g., Brougham \& Walsh, 2009; Damman et al., 2015).

\section{The present research}

In Studies 1 and 2, we test older worker's anticipated identity changes in retirement based on their organizational commitment and social group memberships. In Study 3, we test how retirees have experienced identity changes post-retirement as a function of their past organizational commitment and social group memberships. To assess the robustness of any hypothesized findings, we control for self-esteem and relevant demographic characteristics that might explain anticipated identity changes in retirement. We hypothesize that,

Hypothesis 1 . Older workers high in 9 will anticipate less positive change to their identity in retirement than those low in $9 .{ }^{1}$

Hypothesis 2. There will be an interaction between social group memberships and organizational commitment in predicting anticipated identity changes. Older workers with more group memberships will anticipate more positive changes to their identity in retirement if they have lower organizational commitment compared to those with higher commitment. $^{2}$

Study pre-registrations and data are available in the Online Supplementary Materials on OSF: https://osf.io/ edxs9/?view_only=5bfa5bd7e4ce4453b82a08749b21baad

\footnotetext{
1 This hypothesis corresponds with Study 1, pre-registered Hypothesis 3. All additional hypotheses and analyses are available in the Online Supplementary Materials here.

2 This hypothesis corresponds with Study 1, pre-registered Hypothesis 5. All additional hypotheses and analyses are available in the Online Supplementary Materials here.
}

\section{STUDY 1}

\section{Method}

\section{Participants}

We recruited 591 US participants from Amazon's Mechanical Turk (MTurk) via the TurkPrime user interface. There is considerable evidence across a variety of data and study designs that MTurk provides equivalent or superior data compared to other sources (e.g., Casler et al., 2013; Kees et al., 2017), including in organizational research (Keith et al., 2017), and that any decreases in data reliability and validity can be mitigated by appropriate screening (Chmielewski \& Kucker, 2020). To reduce the possibility of poor data quality, we used the TurkPrime user interface to exclude duplicate IP addresses and suspicious geocode locations and select only workers who were present in the United States with approval rating of $90 \%$ or higher on prior tasks. Participants responded to pre-screening criteria at the beginning of the survey to confirm they were aged between 49 and 70 years, currently in full- or part-time employment and resident of the United States before proceeding. After excluding duplicate records from 80 participants who failed the screening on first attempt because they were either outside of the target age $(N=68)$ or not working $(N=12)$, we were left a final sample of 511 participants (63\% women), with a mean age of 57 years old $(M=57.37, S D=5.23)$. Participants were compensated with $\$ 0.40$ in exchange for their participation in the study, which took around $8 \mathrm{~min}$ to complete. The majority of participants were working full-time (84\%; 16\% part-time), had a household income between $\$ 20,000$ and $\$ 69,000$ (52\%; $41 \% \$ 70,000$ or more; $7 \%$ below $\$ 19,000$ ), and the majority held either an Associate degree or Bachelor's degree (49\%) or had some college education $(23 \% ; 20 \%$ postgraduate education; $9 \%$ high school diploma or lower).

\section{Materials and Procedure}

Participants provided informed consent before completing screening questions for age, country and employment status. We also asked participants to commit to thoughtfully providing their best answers to study questions. Participants who did not pass the screening or integrity check were immediately screened from the study. Eligible participants then completed surveys in a fixed order, measuring organizational commitment, self-esteem, anticipated identity change and group memberships, followed by background and demographic questions (e.g., age, years to retirement, gender, household income, etc.), before being fully debriefed. The study also included measures of social role identification, 
Table 1 Descriptive statistics and correlations for anticipated identity changes among older workers and related measures in Study $1(\mathrm{n}=511)$

\begin{tabular}{lccllllllll}
\hline Variable & Mean & SD & Range & $\alpha$ & 1 & 2 & 3 & 4 & 5 & 6 \\
\hline 1. Anticipated identity change & 0.83 & 0.69 & $-2.40-3.00$ & .91 & - & & & & & \\
2. Self-esteem & 5.79 & 1.08 & $1.10-7.00$ & .92 & $.13^{* *}$ & - & & & & \\
3. Organizational commitment & 4.73 & 1.42 & $1.00-7.00$ & .90 & .05 & $.34^{* *}$ & - & & & \\
4. Group memberships & 2.80 & 2.19 & $0.00-14.00$ & - & $20^{* *}$ & $.09^{*}$ & $.17^{* *}$ & & & \\
5. Years to retirement & 8.30 & 5.75 & $0.00-25.00$ & - & -.01 & -.02 & .08 & .06 & - & \\
6. Household income & - & - & - & - & .09 & $.09^{*}$ & $.12^{* *}$ & $.12^{* *}$ & .03 & - \\
7. Education level & - & - & - & - & .08 & .05 & -.02 & $.25^{* *}$ & $-.05^{*}$ & $.32^{* *}$ \\
\hline
\end{tabular}

Note. ${ }^{* *} p<.01, * p<.05 ; \alpha$ : Scale score reliability, Cronbach's Alpha (not included for single-item measures); See Participants for Household Income and Education career commitment and job commitment. Background, hypotheses and analyses for these variables were pre-registered and results are included in the Online Supplementary Materials. All research described in this article was approved based on requirements set out by the University of Essex Ethics Committee.

Anticipated identity change We based the anticipated identity change scale for this study on a 5-item forecast self-concept content change assessment used in Slotter et al. (2010) to capture changes across five life domains central to identity: social circle, appearance, goals for future, values and beliefs and activities and hobbies (based on James, 1890). We modified the scale to capture positive and negative identity changes rather than how much people expected to change (quantitative). We also expanded the scale, measuring each of the five original domains with four items. Participants indicated how they might change after retirement in terms of social circle (e.g., "The individuals in my social circle"), appearance (e.g., "My concern for my appearance"), goals for future (e.g., "My goals related to my well-being"), values and beliefs (e.g., "The degree to which I appreciate, believe in, and care for others") and activities and hobbies (e.g., "The time I spend or dedicate to new activities or hobbies"). Participants answered each item on a 7-point Likert scale ranging from -3: will change for the worse; to +3: will change for the better with 0: will not change. The scale had a good internal reliability (Cronbach's $\alpha=0.91$ ), and we used the mean score of the 20 items to produce an anticipated identity change score for each participant. The sign of this score indicated the direction of the change: positive scores for participants who expected an average positive change in retirement and negative scores for participants who expected an average negative change.

Organizational commitment Organizational commitment was measured using the Affective Commitment Scale (Allen \& Meyer, 1990). The measure includes eight questions designed to measure worker's attachment to their organiza- tion, e.g., "My organization's problems are mine too". After reverse coding four items, the eight responses were averaged to compute an overall organizational commitment score ranging from 1 to 7 with higher scores indicating greater commitment (Cronbach's $\alpha=0.90$ ).

Self-esteem Participants responded to a 10-item scale designed to measure self-esteem (e.g., "At times I think I am no good at all"; Rosenberg, 1965). Participants expressed their agreement with each statement on a 7-point Likert scale (1: strongly disagree; 7: strongly agree). Mean responses to these ten questions were calculated for each participant (after reverse coding 5 items), with higher mean scores indicating higher self-esteem (Cronbach's $\alpha=0.92$ ).

Group memberships In this task, participants responded to a group membership question based on a listing task by Haslam et al. (2008) to identify the total number of unique social groups to which they belonged. Participants reported the number of groups they considered themselves to be members of. Participants were given 3 group categories to consider: leisure or social groups (e.g., book clubs, gardening clubs, tennis groups, etc.), community groups (e.g., church groups, volunteering, etc.) and work groups (e.g., work teams, professional organizations, alumni, business social groups, etc.). Participants were asked to provide up to a maximum of five groups for each group category (limits based on Steffens et al., 2016), which were then combined to provide a measure of group memberships (maximum of 15 groups).

Means, standard deviations (SD) and correlations between the measures are presented in Table 1 .

\section{Analytic Strategy}

We conducted a stepwise hierarchical regression analysis with anticipated identity changes in retirement as the outcome variable. Continuous variables were mean-centered. In the first step, we entered the main hypothesized 
Table 2 Multiple regression analysis on anticipated identity change in Study 1 preretirement $(\mathrm{N}=511)$

\begin{tabular}{|c|c|c|c|c|c|c|}
\hline \multirow[b]{2}{*}{ Variable } & \multicolumn{2}{|c|}{ Step 1} & \multicolumn{2}{|l|}{ Step 2} & \multicolumn{2}{|l|}{ Step 3} \\
\hline & $B$ & $S E B$ & $B$ & $S E B$ & $B$ & $S E B$ \\
\hline Organizational commitment & .03 & .02 & .01 & .02 & .01 & .02 \\
\hline Group memberships & & & $.06^{* * * *}$ & .01 & $.06^{* * * *}$ & .01 \\
\hline $\begin{array}{l}\text { Organizational commit- } \\
\text { ment } \times \text { Group memberships }\end{array}$ & & & -.00 & .01 & .00 & .01 \\
\hline Education level & & & & & .01 & .02 \\
\hline Household income & & & & & .01 & .01 \\
\hline Gender & & & & & -.01 & .06 \\
\hline Years to retirement & & & & & -.00 & .01 \\
\hline Self-esteem & & & & & $.07^{*}$ & .03 \\
\hline$R^{2}$ & .00 & & .04 & & .05 & \\
\hline $\mathrm{F}$ for $\Delta R^{2}$ & 1.49 & & $9.24^{* * * *}$ & & 1.66 & \\
\hline
\end{tabular}

Note. $* * * p<.001, * * p<.01, * p<.05$ predictor: organizational commitment. For the second step we entered group memberships and the interaction term for work commitment and group memberships to test the hypothesized moderation effect. In the third and final step, we included four demographic predictors associated with retirement wellbeing: education, household income, gender and years to retirement together with self-esteem, to check the robustness of our effects.

\section{Results and discussion}

Overall, we found that older workers largely anticipated positive changes to their identity in retirement $(M=0.83, S D=0.69)$ with $92 \%$ reporting a value above the 'no change' value of ' 0 ' ( $3 \%$ no change; $5 \%$ negative changes, one-sample t-test, $t(510)=27.36, p<0.001)$. We hypothesized that older workers with higher organizational commitment would anticipate less positive changes to their identity following retirement than those less committed, however we found no association between the two (See Table 2, Step 1, $b=0.03, p=0.222$ ). We did find a significant association between group memberships and positive identity changes, such that older workers with more group memberships anticipated more positive changes to their identity in retirement (Table 2, Step $2, b=0.06, p<0.001)$. Contrary to our expectation, the 2-way group membership by work commitment interaction was not significant (Table 2, Step 2, $b=-0.00$, $p=0.737)$. In the final step of our analysis, we added demographic factors shown to influence wellbeing postretirement and self-esteem. Group memberships remained significantly associated with anticipated identity change although self-esteem was also a significant predictor of anticipated identity change in retirement (Table 2, Step $3, b=0.07, p=0.017$ ).

\section{STUDY 2}

Study 1 did not find support for our hypothesis that older workers more committed to their organization anticipated less positive identity change upon entering retirement than those less committed. Study 1 did show that older workers largely anticipated positive changes to their identity in retirement. This positive anticipation of retirement might mean that older workers view retirement less as an exit from their organization and the workforce (involving loss of existing meaning), and more as an entry into a new role of 'retiree'. While life transitions concerning role exits precipitate identity disruption (e.g., job loss, relationship dissolution), transitions that concern role entries (e.g., starting a new job, becoming a parent) do not (Light \& Visser, 2013). Unlike other role exits, retirement from the workforce after a certain age is a societal norm that can bring new opportunities to fulfil personal goals and make positive changes to identity (Brougham \& Walsh, 2009; Haslam, Lam, et al., 2018; Haslam, McMahon, et al., 2018; Mattingly \& Lewandowski, 2013; van Solinge \& Henkens, 2007). Thus, rather than exit from the organization, many older workers may anticipate retirement as an entry into a new life phase and role.

The anticipation of positive identity changes we found in Study 1 suggest that rather than viewing retirement as an exit from the workforce, leading to personal loss, many workers see retiring as entering a new role that provides new opportunities. This makes it difficult to conclude if organizational commitment and social group memberships could mitigate any negative anticipated changes to identity resulting from retirement. As role exits (but not entries) lead to identity disruption (Light \& Visser, 2013), giving older workers a clear reference point to reflect on retirement in terms of either potential losses (through exit) or gains (through entry into retirement) might be expected to 
alter their anticipation (Holmes et al., 2011; Kahneman \& Tversky, 1984). Specifically, using a framing manipulation to define retirement as an exit from the workforce (involving loss and withdrawal) should lead to less positive anticipated identity change, allowing us to better assess the moderating role of organizational commitment and group memberships. In Study 2, we aimed to test whether older workers more committed to their organization would anticipate less positive changes to their identity than those less committed when retirement was being thought about as an exit. Based on existing social identity research (Greenaway et al., 2016; Iyer et al., 2009) we expected that when older workers more committed to their organization consider retirement as an exit from the workforce resulting in loss, alternative group identities might help to buffer any anticipated discontinuity.

Hypothesis 3. Older workers with higher organizational commitment will anticipate less positive change to their identity when retirement is framed as an exit from the workforce. We do not anticipate any effect of organizational commitment when retirement is framed as an entry into retirement. $^{3}$

Hypothesis 4. Organizational commitment, group memberships and framing condition will interact to predict anticipated identity changes in retirement. There will be a significant effect of group memberships when retirement is framed as a work exit, such that older workers with more social groups will anticipate more positive identity changes when high in organizational commitment, compared to those with fewer group memberships. ${ }^{4}$

\section{Method}

\section{Participants}

We aimed to recruit 565 US participants from Amazon's MTurk via the TurkPrime user interface. To reduce the possibility of poor data quality, we used the same TurkPrime exclusions applied in Study 1 and excluded users that had completed the previous study. As in Study 1, participants responded to pre-screening criteria at the beginning of the survey to confirm they were aged between 49 and 70 years, currently in full- or part-time employment and resident of the United States before proceeding. Additional, irrelevant screening questions about relationship status and industry worked in were

\footnotetext{
3 This hypothesis corresponds with Study 2, pre-registered Hypothesis 3a. All additional hypotheses and analyses are available in the Online Supplementary Materials here.

${ }^{4}$ This hypothesis corresponds with Study 2, pre-registered Hypothesis 4ii. All additional hypotheses and analyses are available in the Online Supplementary Materials here.
}

included to reduce the chances of participants guessing study criteria (Keith et al., 2017). Seventeen participants were excluded from the analysis because they failed the screening on first attempt after they reported being outside of the target age $(N=16)$ or not working $(N=1)$. Participants were compensated with $\$ 0.40$ in exchange for their participation in the study, which took around 10 min to complete. This left a final sample of 548 participants (70\% women) with a mean age of 56 years old. $(M=55.90, S D=4.91)$. The majority of participants were working full-time (83\%; 17\% part-time), had a household income between $\$ 20,000$ and $\$ 69,000$ (55\%; $38 \% \$ 70,000$ or more; $7 \%$ below \$19,000), and held either an Associate degree or Bachelor's degree (45\%) or had some college education $(22 \% ; 21 \%$ postgraduate education; $12 \%$ high school diploma or lower).

\section{Materials and Procedure}

Participants provided informed consent before completing screening questions for age, country and employment status. We also asked participants to commit to thoughtfully providing their best answers to study questions. Eligible participants then completed survey measures in a fixed order for organizational commitment, group memberships and selfesteem. Participants were then asked to reflect on how they anticipated the experience of retirement transition before being randomly assigned to either the work exit condition or retirement entry condition.

We designed reflection conditions that would frame the mental representation of retirement with either a negative (loss) or positive (gain) valance. This kind of attribute framing often has a large influence over how information is processed (Levin et al., 1998). In the work exit condition, participants were asked to list three things in their life that they expected to lose when they stopped working that would have a significant impact on their everyday life. In the retirement entry condition, participants were asked to list three things they expected to gain when they retired that would have a significant impact on their everyday life. Participants then completed survey measures for anticipated identity change in retirement. Finally, participants completed some background and demographic questions (e.g., age in years, years to retirement, gender, household income) before being fully debriefed. The study also included measures of social role identification, self-expansion, career commitment and job commitment. Background, hypotheses and analyses for these variables were pre-registered and results are included in the Online Supplementary Materials.

All measures were the same as those used in Study 1, with the addition of the framing task.

Means, standard deviations (SD) and correlations between the measures are presented in Table 3 . 
Table 3 Descriptive statistics and correlations for anticipated identity changes among older workers and related measures in Study $2(\mathrm{n}=548)$

\begin{tabular}{lllllllllll}
\hline Variable & Mean & SD & Range & $\alpha$ & 1 & 2 & 3 & 4 & 5 & 6 \\
\hline 1. Anticipated identity change & .82 & .75 & $-2.25-3.00$ & .92 & - & & & & & \\
2. Self-esteem & 5.68 & 1.09 & $1.40-7.00$ & .91 & $.29^{* *}$ & - & & & & \\
3. Organizational commitment & 4.80 & 1.35 & $1.00-7.00$ & .89 & $.12^{* *}$ & $.28^{* *}$ & - & & & \\
4. Group memberships & 2.87 & 2.19 & $0.00-14.00$ & - & $.15^{* *}$ & $.12^{* *}$ & $.24^{* *}$ & - & & \\
5. Years to retirement & 10.02 & 6.20 & $0.00-25.00$ & - & $-.13^{* *}$ & $-.10^{*}$ & -.01 & $-.08^{*}$ & - & \\
6. Household income & - & - & - & - & -.01 & $.10^{*}$ & .08 & $.20^{* *}$ & -.07 & - \\
7. Education level & - & - & - & - & .01 & $.07^{\wedge}$ & .06 & $.29^{* *}$ & -.07 & $.36^{* *}$ \\
\hline
\end{tabular}

Note. ${ }^{* *} p<.01, * p<.05 ; \alpha$ : Internal consistency, Cronbach's Alpha (not included for single-item measures); See Participants for Household Income and Education

\section{Analytic Strategy}

The same analytical approach was employed as was used for Study 1. Continuous variables were mean-centered and the framing condition variable dummy-coded $(0=$ exit condition, $1=$ entry condition). In the first step, we entered the main hypothesized predictors: organizational commitment and framing condition, together with their interaction term. For the second step we entered group memberships and the two- and three-way interaction terms with work commitment and condition to test if social group memberships moderated the relationship between organizational commitment and anticipated identity change. In the third and final step, we again included sociodemographic predictors and self-esteem.

\section{Results and discussion}

Before testing our hypotheses, we first checked the main effect of framing condition on anticipated identity change (see Fig. 1). The framing condition was effective, with participants in the work exit condition forecasting significantly less positive change than participants in the retirement entry condition, $M=0.64, S D=0.78$, vs., $M=1.01, S D=0.67 ; t$ $(546)=5.94, p<0.001 ; d=0.51$.

We hypothesized that in the work exit condition, older workers more committed to their organization would anticipate less positive changes to their identity following retirement than those less committed. Our results showed a pattern that workers with higher organizational commitment had slightly less positive anticipation of identity change in retirement when thinking about retirement as a role exit, and slightly more positive anticipated change when thinking about retirement in the context of a role entry when compared to those less committed (see Fig. 2). However, we did not find significant support for our hypothesis, with no interaction between organizational commitment and framing condition (Table 4, Step 1, $b=0.03, p=0.515$ ).

We next set out to test the hypothesis that in the work exit condition, older workers who were more committed to their organization would anticipate more positive identity changes when they had greater, compared to fewer group memberships. Regression analysis revealed a significant three-way interaction between framing condition, organizational commitment and group memberships predicting anticipated identity change (Table 4 , Step $2, b=0.05$, $p=0.017$ ). To test our hypothesis, we first decomposed the 3 -way interaction to test whether the 2-way organizational commitment by group membership interaction was significant for people in the exit and entry framing conditions (Fig. 2). The interaction between organizational commitment and group memberships was, as hypothesized, significant when retirement was framed as a work exit $(b=-0.04$, $p=0.015)$ but not as a retirement entry $(b=0.01, p=0.395)$. To test for the hypothesized simple effect of group membership on those with higher organizational commitment, we further decomposed the 2-way interactions for people high (+1SD) and low (+1SD) in commitment. Contrary to our hypothesis, in the work exit condition, older workers higher in organizational commitment did not anticipate more positive identity changes in retirement when they belonged to

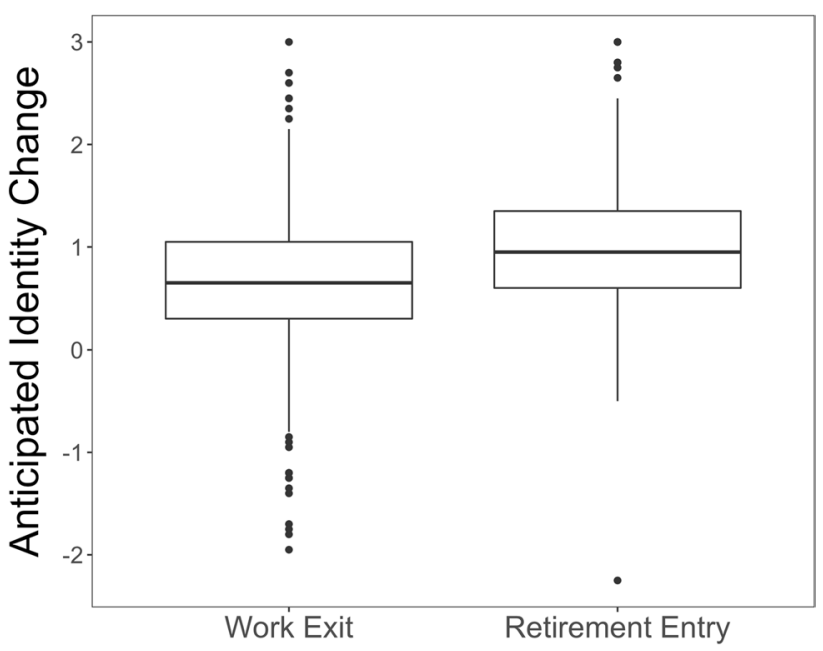

Fig. 1 Boxplot distribution of anticipated identity change responses in work exit and retirement entry conditions 

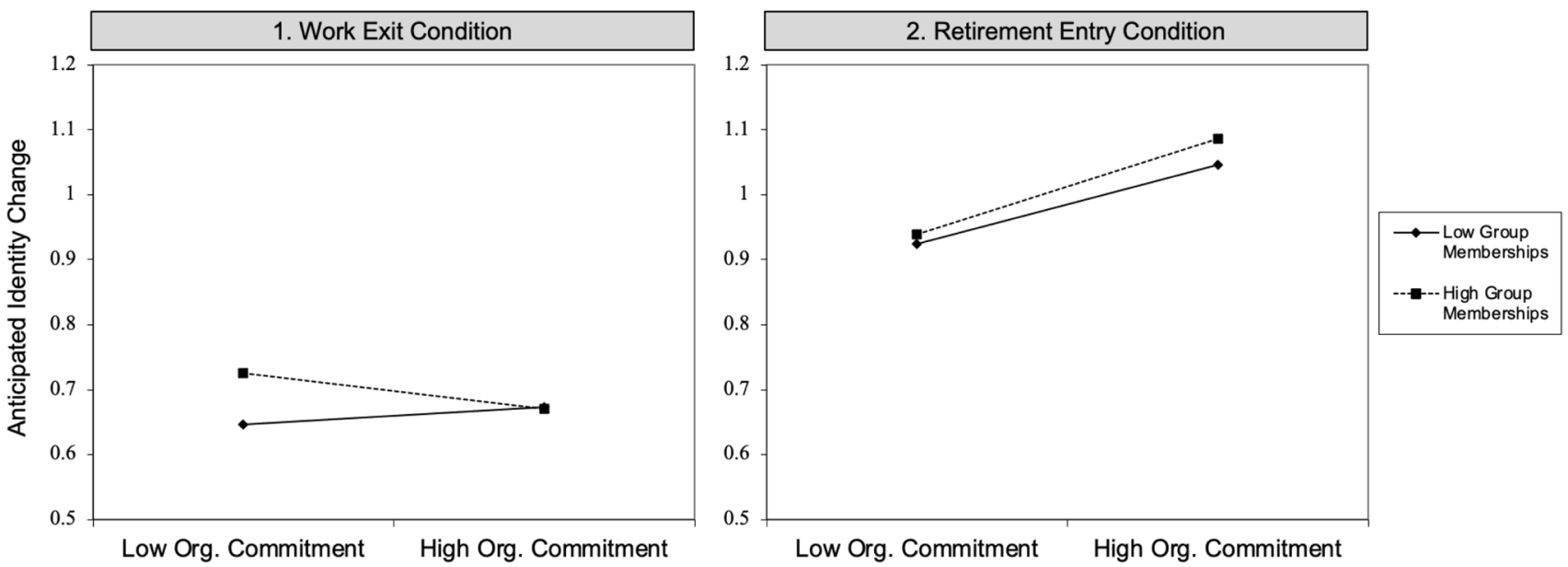

Fig. 2 Interaction between framing condition, organizational commitment, group memberships predicts anticipated changes to identity in retirement (high and low values of organizational commitment and group memberships represented at $\pm 1 \mathrm{SD}$ )

Table 4 Multiple linear regression analysis on anticipated identity change in Study 2 pre-retirement with framing condition $(\mathrm{N}=548)$

\begin{tabular}{|c|c|c|c|c|c|c|}
\hline \multirow[b]{2}{*}{ Variable } & \multicolumn{2}{|l|}{ Step 1} & \multicolumn{2}{|l|}{ Step 2} & \multicolumn{2}{|l|}{ Step 3} \\
\hline & $B$ & $S E B$ & $B$ & $S E B$ & $B$ & $S E B$ \\
\hline Framing condition (entry / exit) & $.36^{* * *}$ & .06 & $.32^{* * *}$ & .06 & $.31^{* * *}$ & .06 \\
\hline Organizational commitment & .05 & .03 & .01 & .03 & -.03 & .03 \\
\hline Group memberships & & & $.04^{\wedge}$ & .02 & .03 & .02 \\
\hline Condition $\times$ Organizational commitment & .03 & .05 & .05 & .05 & .06 & .05 \\
\hline Condition $\times$ Group memberships & & & -.01 & .03 & -.01 & .03 \\
\hline Organizational commitment $\times$ Group memberships & & & $-.04^{* *}$ & .02 & $-.04^{* *}$ & .02 \\
\hline Condition $\times$ Organizational commitment $\times$ Group memberships & & & $.05^{*}$ & .03 & $.05^{*}$ & .02 \\
\hline Education level & & & & & -.02 & .02 \\
\hline Household income & & & & & -.01 & .01 \\
\hline Gender & & & & & .06 & .07 \\
\hline Years to retirement & & & & & $-.01^{*}$ & .01 \\
\hline Self-esteem & & & & & $.18^{* * *}$ & .03 \\
\hline$R^{2}$ & .07 & .10 & .17 & & & \\
\hline $\mathrm{F}$ for $\Delta R^{2}$ & $14.15^{* * *}$ & $3.45^{* *}$ & $9.79^{* * *}$ & & & \\
\hline
\end{tabular}

Note. $* * * p<.001, * * p<.01, * p<.05$

more, relative to fewer social groups $(b=-0.02, p=0.608)$. However, the simple effect of group membership was significant for less committed workers $(b=0.09, p<0.003)$, such that less committed workers in the exit framing condition reported more positive anticipated changes to their identity in retirement when they belonged to more, relative to fewer social groups.

In the final step of our analysis (Table 4, Step 3), we added demographic factors and self-esteem to test for the robustness of our effects. While self-esteem was again a significant predictor of anticipated identity change in retirement $(b=0.18, p<0.001)$, with older workers with higher self-esteem anticipating more positive identity changes, the three-way interaction between condition, organizational commitment and group memberships remained significant $(b=0.05, p=0.021)$.

The aim of Study 2 was to understand anticipation of identity change based on the transition to retirement being framed as either an exit from work role or an entry into retirement role. Higher organizational commitment was not significantly associated with less positive anticipated identity changes when retirement was framed as an exit from the workforce rather than an entry into the role of retiree (see Fig. 2). However, the introduction of group memberships 
revealed a significant three-way interaction, such that when retirement was framed as a work exit, less committed older workers anticipated more positive identity changes when they had greater (rather than fewer) group memberships. The framing of retirement as a 'work exit' in Study 2 helped to explain the results of Study 1 by showing that rather than buffering against identity discontinuity for more committed workers, more group memberships led older workers with low organizational commitment thinking about retirement as an 'exit' to anticipate more positive changes to their identity in retirement, when presumably they will have more time to invest in these important memberships.

\section{STUDY 3}

Studies 1 and 2 found that overall, older workers anticipate positive changes to identity in retirement, and that how positively these changes are anticipated can be associated with their commitment to their organization and their social group memberships. However, previous research has shown errors in affective forecasting, with people often overestimating the good that a future event (like retirement) will have on their lives (Wilson \& Gilbert, 2005). Anticipating retirement as a positive event might lead older workers to overlook the influence of broader life circumstances on their identity (Gilbert \& Wilson, 2007) and result in sub-optimal decisions around investment in professional development, continued work and the timing of retirement. Given this, we next set out to evaluate the actual experience of retirees' identity changes in retirement and compare these to our findings from Studies 1 and 2 about how older workers anticipate these changes. While Studies 1 and 2 did not find that higher organizational commitment was associated with less positive anticipated changes to identity in retirement, in Study 3 we aimed to test this relationship post-retirement by asking retirees to reflect on their commitment pre-retirement and reporting their identity changes experienced.

Hypothesis 5. Retirees high in organizational commitment prior to retirement will experience less positive change to their identity post-retirement than those low in commitment. ${ }^{5}$

Hypothesis 6. Retirees with more group memberships will experience more positive change to their identity postretirement than those with fewer group memberships. ${ }^{6}$

\footnotetext{
5 This hypothesis corresponds with Study 3, pre-registered Hypothesis 1a. All additional hypotheses and analyses are available in the Online Supplementary Materials here.

6 This hypothesis corresponds with Study 3, pre-registered Hypothesis 3a. All additional hypotheses and analyses are available in the Online Supplementary Materials here.
}

Study pre-registration and data are available here: https:// osf.io/edxs9/?view_only=5bfa5bd7e4ce4453b82a08749 b21baad

\section{Method}

\section{Participants}

We recruited 246 US participants from Amazon's Mechanical Turk (Mturk) via TurkPrime. Participants responded to pre-screening criteria at the beginning of the survey to confirm they were US residents, aged between 54 and 75 years and currently retired before proceeding. To reduce the possibility of poor data quality, we again used industry worked in as an irrelevant screening question and applied the same TurkPrime exclusions used in Studies 1 and 2, including participation in these studies. We excluded thirty-one of these participants from the analysis for failing to meet the screening on first attempt because they reported being outside of the target age $(N=16)$, or not working immediately prior to retirement $(N=15)$. Participants were compensated with $\$ 0.40$ in exchange for their participation in the study, which took around $10 \mathrm{~min}$ to complete. Due to the limited number of 'retired' participants active on Mturk, our prescreening delivered a final sample of 215 participants (67\% women) with a mean age of 64 years old $(M=63.88, S D=4.95)$. The majority of participants were working full time immediately prior to retirement $(87 \% ; 13 \%$ part time), had a household income between $\$ 20,000$ and $\$ 69,000$ (58\%; $28 \% \$ 70,000$ or more; $14 \%$ below $\$ 19,000$ ), and the majority held either an Associate degree or Bachelor's degree (46\%) or had some college education (25\%; $18 \%$ postgraduate education; $9 \%$ high school diploma or lower).

\section{Materials and Procedure}

The same procedure was used as Study 1, with questions for work commitment and identity change adapted to the pasttense, so that participants were asked to reflect on their level of commitment immediately prior to retirement and to indicate how much they had experienced identity changes since retirement. The study also included additional measures of social role identification, self-concept (identity) clarity, career commitment and job commitment. Background, hypotheses and analyses for these variables were pre-registered and results are included in the Online Supplementary Materials.

Means, standard deviations (SD) and correlations between the measures are presented in Table 5 .

\section{Analytic Strategy}

The same analytic strategy was employed as in Study 1 to test identity change experienced in retirement. 
Table 5 Descriptive statistics and correlations for experienced identity changes among retirees and related measures in Study 3 $(\mathrm{n}=215)$
Table 6 Multiple regression on experienced identity change in Study 3 post-retirement $(\mathrm{N}=215)$

\begin{tabular}{lclllllllll}
\hline Variable & Mean & SD & Range & $\alpha$ & $(1)$ & $(2)$ & $(3)$ & (4) & (5) & (6) \\
\hline 1. Experienced identity change & 0.50 & 0.78 & $-2.95-3.00$ & .90 & - & & & & & \\
2. Self-esteem & 5.72 & 1.13 & $1.30-7.00$ & .92 & $.35^{* *}$ & - & & & & \\
3. Organizational commitment & 4.86 & 1.05 & $1.45-6.82$ & .93 & -.02 & $.15^{*}$ & - & & & \\
4. Group memberships & 2.01 & 1.91 & $0.00-10.00$ & - & $28^{* *}$ & .12 & .03 & - & & \\
5. Years since retirement & 5.94 & 5.13 & $0.00-25.00$ & - & -.09 & -.11 & $.23^{* *}$ & $-.19^{* *}$ & - & \\
6. Household income & - & - & - & - & -09 & .07 & .04 & $.21^{* *}$ & $-.14^{*}$ & - \\
7. Education level & - & - & - & - & -02 & .04 & -.06 & $.27^{* *}$ & $-.21^{* *}$ & $.31^{* *}$ \\
\hline
\end{tabular}

Note. ${ }^{* *} p<.01, * p<.05 ; \alpha$ : Internal consistency, Cronbach's Alpha (not included for single-item measures); See Participants for Household Income and Education

\begin{tabular}{|c|c|c|c|c|c|c|}
\hline \multirow[b]{2}{*}{ Variable } & \multicolumn{2}{|c|}{ Step 1} & \multicolumn{2}{|l|}{ Step 2} & \multicolumn{2}{|l|}{ Step 3} \\
\hline & $B$ & $S E B$ & $B$ & $S E B$ & $B$ & $S E B$ \\
\hline Organizational commitment & .04 & .04 & .02 & .04 & -.02 & .04 \\
\hline Group memberships & & & $.12^{* * *}$ & .03 & $.11^{* * *}$ & .03 \\
\hline $\begin{array}{l}\text { Organizational commit- } \\
\text { ment } \times \text { Group memberships }\end{array}$ & & & -.02 & .02 & -.03 & .02 \\
\hline Education level & & & & & -.04 & .04 \\
\hline Household income & & & & & .02 & .02 \\
\hline Gender & & & & & .18 & .11 \\
\hline Years from retirement & & & & & -.00 & .01 \\
\hline Self-esteem & & & & & $.24^{* * *}$ & .04 \\
\hline$R^{2}$ & .00 & & .09 & & .21 & \\
\hline $\mathrm{F}$ for $\Delta R^{2}$ & 0.98 & & $9.28^{* * * *}$ & & $6.31^{\text {**** }}$ & \\
\hline
\end{tabular}

Note. $* * * p<.001, * * p<.01, * p<.05$

\section{Results and discussion}

Overall, retirees reported experiencing positive changes to their identity post-retirement (Table $5, M=0.50$, $S D=0.78$ ) with $80 \%$ reporting positive changes ( $1 \%$ no change; $19 \%$ negative changes). We confirmed the significance of this with a one-sample t-test against a value of ' 0 ', $t(214)=9.34, p<0.001$. However, these changes were significantly less positive than anticipated by older workers pre-retirement (Table $1, M=0.83, S D=0.75$ ), $t(725)=5.26$, $p<0.001 ; d=0.43)$. This suggests that while retirement is a major life milestone for which older adults anticipate significant positive changes to their identity, the changes experienced in retirement might not match those anticipated.

Our Study 3 results did not support our hypothesis that retirees who were more committed to their organization prior to retirement would report experiencing less positive identity changes after leaving the workforce. Our regression analysis showed no significant association between prior organizational commitment and identity changes experienced in retirement (Table 6, Step 1, $b=0.04, p=0.322$ ). In step two of our analysis, we entered group memberships together with its interaction with work commitment.
Consistent with our hypothesis and results from Study 1, retirees with more group memberships reported experiencing significantly more positive identity changes in retirement (Table 6, Step 2, $b=0.12, p<0.001$ ), but there was no significant interaction between organizational commitment and group memberships (Table 6, Step 2, $b=-0.02, p=0.400$ ). In the final step of our analysis, we added demographic factors and self-esteem. While self-esteem was a significant predictor of identity change experienced post-retirement (Table 6, Step $3, b=0.24, p<0.001$ ), the effect of group membership on experienced identity change remained significant.

\section{Discussion}

The aim of these studies was to examine the relationship between organizational commitment and anticipated identity changes in retirement among older workers, as well as any moderating effect of social group memberships. When commitment is high, loss of an important source of meaning, such as work, can cause a disruption to identity continuity (Barnes \& Parry, 2004; McIntyre et al., 2014; Slotter et al., 2010), and we therefore expected older workers with 
higher levels of organizational commitment to anticipate less positive changes to their identity in retirement than those less committed. We also expected this relationship to be moderated by social group memberships. Specifically, for less committed older workers, retirement might present the opportunity to increase investment in these groups leading to more positive anticipation (Study 1), or when thinking about retirement as an exit resulting in loss, more groups might help to buffer any discontinuity anticipated by those more committed to their organization (Study 2).

Consistently, we found no direct association between organizational commitment and identity changes in retirement, either anticipated by older workers prior to retirement or experienced afterwards. However, we found that this association was dependent on the framing of retirement as either an exit from the workforce or an entry into retirement for older workers, and the number of social group memberships held. Although higher organizational commitment among older workers was not associated with more negative anticipated identity changes in retirement, framing retirement as either an exit or entry had different effects depending on individual organizational commitment and group memberships. When thinking about retirement as an exit, those with low organizational commitment anticipated more positive changes when they had more (rather than fewer) group memberships. Across all studies, older adults with more group memberships anticipated and experienced more positive changes to identity in retirement.

\section{Theoretical Implications}

Our findings have three main theoretical implications. First, rather than older workers being simply motivated to maintain continuity in retirement (Atchley, 1989; Feldman, 1994), our findings suggest older workers anticipate that they will change after leaving the workforce and that these changes will mostly be positive. Retirement has traditionally been conceptualized as a life transition involving a role exit (Wang \& Shi, 2014), but unlike other exits (e.g., relationship dissolution; Slotter et al., 2010), our findings show that older workers view retirement positively as an entry into a new life phase. Past research has shown that unlike role exits, role entries do not carry the same potential for identity disruption and reduced wellbeing outcomes (Light \& Visser, 2013). Although role exits are believed to be disruptive, we found that framing retirement as an exit only decreased older worker's anticipation of positive change, and did not lead to anticipation of negative change, highlighting the optimism of older workers towards retirement. These results extend previous findings that older workers largely expect to enjoy retirement (Taylor \& Shore, 1995), and see the transition as an opportunity to pursue new life goals (Brougham \& Walsh, 2009).
Secondly, our findings add another dimension to continuity models of retirement that associate older worker's job attitudes with their retirement intentions (Atchley, 1989; Bal et al., 2012; Feldman \& Beehr, 2011). Specifically, although past findings have shown that older workers with higher affective commitment to their organization have greater intention to continue working with their organization beyond retirement age (Jones \& McIntosh, 2010; Zhan et al., 2013), our findings demonstrate that more committed workers still anticipate positive self-changes when they do (eventually) retire. This supports past findings that older workers can hold positive attitudes to both work and retirement simultaneously (Adams et al., 2002), and our results suggest that the relationship between older worker's commitment to their organization and later retirement intentions does not mean that they anticipate that retirement (when it comes) will be a source of discontinuity.

Finally, these findings further social identity research showing the importance of group memberships to older adults in retirement (Haslam et al., 2019; Haslam, Lam, et al., 2018; Haslam, McMahon, et al., 2018; Steffens et al., 2016). While multiple groups have previously been thought to support wellbeing by providing identity continuity in retirement transition (Atchley, 1989; Henning, Lindwall, \& Johansson, 2016; Steffens et al., 2016), our studies show that greater group memberships are also associated with older workers anticipating more positive changes to themselves in retirement, over and above any affective commitment to the organization. Study 3 confirmed that group memberships were a significant predictor of experienced positive identity changes among retirees, even after controlling for self-esteem, income and education. Our findings that group memberships predict anticipated and experienced identity change are in line with previous findings that these group memberships provide opportunities to contribute positively to identity and wellbeing by engaging in novel and interesting activities with others (Mattingly \& Lewandowski, 2013, 2014), identifying as a 'retiree' (Haslam et al., 2018; Haslam, McMahon, et al., 2018), and giving and receiving social support (Steffens et al., 2016).

\section{Implications for Practice}

The anticipation of positive identity changes in retirement has consequences for retirement preparation and decisionmaking. Consistent with research on affective forecasting (Wilson \& Gilbert, 2005), our studies found that identity changes experienced by retirees post-retirement were not as positive as anticipated by older workers, notwithstanding that like forecasting errors, memory errors also tend to be positively biased (e.g., enhanced memory for positive events; Mather \& Carstensen, 2005, and 'rosy view' with the passing of time; Mitchell et al., 1997). Our findings suggest that 
in anticipating positive identity changes in retirement, older workers might view social group memberships and leisure activities as alternatives to employment, leading to lower intention to continue working (Katz et al, 2019; Seongsu \& Feldman, 2000). This might mean missing out on interesting and fulfilling opportunities, with evidence that engaging in part-time work after retirement age increases post-retirement satisfaction and wellbeing (e.g., Dingemans \& Henkens, 2015; Seongsu \& Feldman, 2000). Additionally, our findings suggest that thinking about retirement as an entry into a new life phase can create positive retirement anticipation for older workers, including those with high organizational commitment and associated traits (self-esteem, group memberships). With organizations being challenged to find ways to extend working lives (Pak et al., 2020), our results suggest HR managers may find some of their most committed older workers are those most eagerly anticipating their entry into retirement. While research evaluating the effectiveness of retirement preparation and planning programs is limited (Leandro-França et al., 2016), there is some evidence that such programs can lead to lower, more realistic expectations of post-retirement opportunities (Cohen-Mansfield \& Regev, 2018).

Our findings also contribute to a growing literature on the importance of social groups, and the social support they provide, to retirement identity and wellbeing (Haslam et al., 2019; Haslam, Lam, et al., 2018; Haslam, McMahon, et al., 2018; Jetten et al., 2015), despite these often being perceived by the public to be far less important for health and wellbeing than they actually are (Haslam et al., 2018; Haslam, McMahon, et al., 2018). Social groups are especially beneficial post-retirement when they involve shared group activities (Haslam et al., 2019). Consistent with the link found between social group memberships and positive anticipation and experience of identity change in retirement, having a variety of activities positively shapes general retirement expectations and contributes to healthy post-retirement aging (Beier et al., 2018), while sharing these activities with a partner can increase relationship satisfaction (Bozoglan, 2015). Interventions pre- and post-retirement that aim to preserve work-based group affiliations (e.g., alumni) and increase the number of social groups and subsequent activities in which people participate (e.g., volunteer pathways, retiree community groups) might provide opportunities for older adults to continue to make positive contributions towards their community and identity after exiting the workforce.

\section{Limitations}

Given our study was not longitudinal, post-retirement participants in Study 3 were a few years past retirement transition and any short-term identity changes in the period immediately following retirement as a result of prior organizational commitment would not have been captured. Previous studies have focused on identity disruption within the first 12 months of exit (e.g., Light \& Visser, 2013; Slotter et al., 2010) and some studies have shown negative effects of retirement on wellbeing within the first 12 months, before a recovery trend (e.g., Richardson \& Kilty, 2005; Wang, 2007). Thus, a cross-sectional or a longitudinal study that looks at participants immediately after retirement transition might find greater evidence of identity disruption for those more committed to their organization.

Secondly, all studies were conducted with an online sample of MTurk users in the United States. Participants in these studies were rigorously pre-screened and MTurk provides socio-economically diverse sample characteristics (Casler et al., 2013; Chandler \& Shapiro, 2016). However, it is possible that particular factors in this US MTurk population (e.g., higher levels of education and underemployment; Shapiro et al., 2013) might pre-dispose workers to different ways of thinking about work and retirement when compared the general population (e.g., greater education can provide opportunities in retirement; Wang \& Shi, 2014). Our findings show that lower levels of education can be associated with fewer social group memberships, and we might expect that for older workers with lower education levels, social group memberships might be even more important to the positive anticipation of identity change in retirement. Further research should investigate the role of education and under-employment on anticipated and experienced identity change in retirement. Participants in our studies also received low levels of compensation (around $\$ 2.60$ per hour), typical on platforms such as MTurk at the time of data collection (Hara et al., 2018). The ethics of these practices have been questioned in recent years (Giner-Sorolla, 2019; Williamson, 2016), and we largely support the call for higher participant payments in the social sciences.

\section{Future directions}

This research suggests that the changes older workers anticipate in retirement, and the plans and decisions they make based on this anticipation, are likely to be shaped by how they feel about themselves, their organization and the important social identities they hold outside of work. However, with paths to retirement undergoing increasing changes due to ageing populations, older workers will not necessarily jump from full time employment with their organization into retirement upon reaching a statutory age (Henkens et al., 2018). In many countries, the minimum retirement age is increasing, and more people are choosing to engage in work activities beyond the traditional 
retirement age (Truxillo et al., 2015). Rather than a hard exit from the workforce, retirement transitions can now include periods of part-time work with new or former employers, and self-employment (Feldman \& Beehr, 2011; Kanfer et al., 2013). Thus, future studies might examine how these different retirement prospects and pathways might affect the identity changes anticipated by older workers and their subsequent retirement decisions. Additionally, more longitudinal studies and experimental designs are needed that specifically consider how anticipation of post-retirement changes and the perception of retirement as either an exit or entry shape retirement intentions, decisions and outcomes.

\section{Conclusion}

In conclusion, the present findings contribute to existing psychological literature on retirement and identity by showing how organizational commitment, group memberships and framing influence older worker's anticipated identity changes in retirement. Specifically, that when organizational commitment is low, those with more group memberships anticipate changes to their identity in retirement more positively than those with fewer group memberships when thinking about what will be lost upon exiting the workforce. Additionally, the identity changes that await in retirement might not be as positive as anticipated by older workers, however having more group memberships is associated with both older workers' anticipation and retirees' experience of more positive change.

Supplementary Information The online version contains supplementary material available at https://doi.org/10.1007/s12144-022-02869-7.

Funding The author(s) received no financial support for the research, authorship, and/or publication of this article.

\section{Declarations}

Conflict of Interests The author(s) declared no potential conflicts of interest with respect to the research, authorship, and/or publication of this article.

Open Access This article is licensed under a Creative Commons Attribution 4.0 International License, which permits use, sharing, adaptation, distribution and reproduction in any medium or format, as long as you give appropriate credit to the original author(s) and the source, provide a link to the Creative Commons licence, and indicate if changes were made. The images or other third party material in this article are included in the article's Creative Commons licence, unless indicated otherwise in a credit line to the material. If material is not included in the article's Creative Commons licence and your intended use is not permitted by statutory regulation or exceeds the permitted use, you will need to obtain permission directly from the copyright holder. To view a copy of this licence, visit http://creativecommons.org/licenses/by/4.0/.

\section{References}

Adams, G. A., Prescher, J., Beehr, T. A., \& Lepisto, L. (2002). Applying work-role attachment theory to retirement decision-making. International Journal of Aging \& Human Development, 54(2), 125-137. https://doi.org/10.2190/JRUQ-XQ2N-UP0A-M432

Allen, N. J., \& Meyer, J. P. (1990). The measurement and antecedents of affective, continuance and normative commitment to the organization. Journal of Occupational Psychology, 63(1), 1-18. https://doi.org/10.1111/j.2044-8325.1990.tb00506.x

Amiot, C. E., de la Sablonniere, R., Smith, L. G. E., \& Smith, J. R. (2015). Capturing changes in social identities over time and how they become part of the self-concept. Social and Personality Psychology Compass, 9(4), 171-187. https://doi.org/10.1111/spc3.12169

Atchley, R. C. (1989). A Continuity Theory of Normal Aging. The Gerontologist, 29(2), 183-190. https://doi.org/10.1093/geront/ 29.2.183

Barnes, H., \& Parry, J. (2004). Renegotiating identity and relationships: Men and women's adjustments to retirement. Ageing and Society, 24(2), 213-233. https://doi.org/10.1017/S0144686X0300148X

Bal, P. M., de Jong, S. B., Jansen, P. G., \& Bakker, A. B. (2012). Motivating employees to work beyond retirement: A multi-level study of the role of I-deals and unit climate. Journal of Management Studies, 49(2), 306-331. https://doi.org/10.1111/j.1467-6486. 2011.01026.x

Bal, P. M., de Lange, A. H., Zacher, H., \& Van der Heijden, B. I. J. M. (2013). A lifespan perspective on psychological contracts and their relations with organizational commitment. European Journal of Work and Organizational Psychology, 22(3), 279-292. https:// doi.org/10.1080/1359432X.2012.741595

Beier, M. E., Torres, W. J., \& Gilberto, J. M. (2018). Activities matter: Personality and resource determinants of activities and their effect on mental and physical well-being and retirement expectations. Work, Aging and Retirement, 4(1), 67-78. https://doi.org/10.1093/ workar/waw034

Bonsang, E., \& Klein, T. J. (2012). Retirement and subjective wellbeing. Journal of Economic Behavior and Organization, 83(3), 311-329. https://doi.org/10.1016/j.jebo.2012.06.002

Bozoglan, B. (2015). Spousal intrusion as a predictor of wives' marital satisfaction in their spouses' retirement. Psychological Reports, 116(3), 921-935. https://doi.org/10.2466/21.PR0.116k28w1

Brougham, R. R., \& Walsh, D. A. (2009). Early and Late Retirement Exits. The International Journal of Aging and Human Development, 69(4), 267-286. https://doi.org/10.2190/AG.69.4.b

Butzer, B., \& Kuiper, N. A. (2006). Relationships between the frequency of social comparisons and self-concept clarity, intolerance of uncertainty, anxiety, and depression. Personality and Individual Differences. https://doi.org/10.1016/j.paid.2005.12.017

Campbell, J. D., Assanand, S., \& Paula, A. D. (2003). The structure of the self-concept and its relation to psychological adjustment. Journal of Personality, 71(1), 115-140. https://doi.org/10.1111/ 1467-6494.t01-1-00002

Casler, K., Bickel, L., \& Hackett, E. (2013). Separate but equal? A comparison of participants and data gathered via Amazon's MTurk, social media, and face-to-face behavioral testing. Computers in Human Behavior, 29(6), 2156-2160. https://doi.org/10. 1016/J.CHB.2013.05.009

Chandler, J., \& Shapiro, D. (2016). Conducting Clinical Research Using Crowdsourced Convenience Samples. Annual Review of Clinical Psychology, 12(1), 53-81. https://doi.org/10.1146/annur ev-clinpsy-021815-093623

Chang, C. H., Ferris, D. L., Johnson, R. E., Rosen, C. C., \& Tan, J. A. (2012). Core self-evaluations: A review and evaluation of the literature. Journal of Management, 38(1), 81-128. https://doi.org/ $10.1177 / 0149206311419661$ 
Chmielewski, M., \& Kucker, S. C. (2020). An MTurk crisis? Shifts in data quality and the impact on study results. Social Psychological and Personality Science, 11(4), 464-473. https://doi.org/10.1177/ 1948550619875149

Cohen-Mansfield, J., \& Regev, I. (2018). Retirement Preparation Programs: An Examination of Retirement Perceptions, Self-Mastery, and Well-Being. Research on Social Work Practice, 28(4), 428437. https://doi.org/10.1177/1049731516645194

Conroy, S. A., \& O'Leary-Kelly, A. M. (2014). Letting go and moving on: Work-related identity loss and recovery. Academy of Management Review, 39(1), 67-87. https://doi.org/10.5465/amr.2011. 0396

Damman, M., Henkens, K., \& Kalmijn, M. (2015). Missing work after retirement: The role of life histories in the retirement adjustment process. The Gerontologist, 55(5), 802-813. https://doi.org/10. 1093/geront/gnt169

Dave, D., Rashad, I., \& Spasojevic, J. (2006). The effects of retirement on physical and mental health outcomes (No. w12123). National Bureau of Economic Research. https://doi.org/10.2139/ssrn.1024475

DeMarree K.G., \& Bobrowski M.E. (2017) Structure and Validity of Self-Concept Clarity Measures. In: Lodi-Smith J., DeMarree K. (eds) Self-Concept Clarity. Springer, Cham. https://doi.org/10. 1007/978-3-319-71547-6_1

Dingemans, E., \& Henkens, K. (2015). How do retirement dynamics influence mental well-being in later life? A 10-year panel study. Scandinavian Journal of Work, Environment and Health, 41(1), 16-23. https://doi.org/10.5271/sjweh.3464

Feldman, D. C. (1994). The decision to retire early: A review and conceptualization. Academy of Management Review, 19(2), 285-311. https://doi.org/10.5465/AMR.1994.9410210751

Feldman, D. C., \& Beehr, T. A. (2011). A Three-Phase Model of Retirement Decision Making. American Psychologist, 66(3), 193-203. https://doi.org/10.1037/a0022153

Gilbert, D. T., \& Wilson, T. D. (2007). Prospection: Experiencing the future. Science, 317(5843), 1351-1354. https://doi.org/10.1126/ science. 1144161

Giner-Sorolla, R. (2019). From crisis of evidence to a "crisis" of relevance? Incentive-based answers for social psychology's perennial relevance worries. European Review of Social Psychology, 30(1), 1-38. https://doi.org/10.1080/10463283.2018.1542902

Greenaway, K. H., Cruwys, T., Haslam, S. A., \& Jetten, J. (2016). Social identities promote well-being because they satisfy global psychological needs. European Journal of Social Psychology, 46(3), 294-307. https://doi.org/10.1002/ejsp.2169

Haslam, C., Holme, A., Haslam, S. A., Iyer, A., Jetten, J., \& Williams, W. H. (2008). Maintaining group memberships: Social identity continuity predicts well-being after stroke. Neuropsychological Rehabilitation, 18(5-6), 671-691. https://doi.org/10.1080/09602 010701643449

Haslam, C., Lam, B. C., Branscombe, N. R., Steffens, N. K., Haslam, S. A., Cruwys, T., Fong, P., \& Ball, T. C. (2018a). Adjusting to life in retirement: The protective role of new group memberships and identification as a retiree. European Journal of Work and Organizational Psychology, 27(6), 822-839. https://doi.org/10. 1080/1359432X.2018.1538127

Haslam, S. A., McMahon, C., Cruwys, T., Haslam, C., Jetten, J., \& Steffens, N. K. (2018b). Social cure, what social cure? The propensity to underestimate the importance of social factors for health. Social Science \& Medicine, 198, 14-21.

Haslam, C., Steffens, N. K., Branscombe, N. R., Haslam, S. A., Cruwys, T., Lam, B. C. P., Pachana, N. A., \& Yang, J. (2019). The Importance of Social Groups for Retirement Adjustment: Evidence, Application, and Policy Implications of the Social Identity Model of Identity Change. Social Issues and Policy Review, 13(1), 93-124. https://doi.org/10.1111/sipr.12049
Hara, K., Adams, A., Milland, K., Savage, S., Callison-Burch, C., \& Bigham, J. P. (2018). A data-driven analysis of workers' earnings on Amazon Mechanical Turk. In Proceedings of the 2018 CHI conference on human factors in computing systems, Paper 449, 1-14, ACM. https://doi.org/10.1145/3173574.3174023

Heller-Sahlgren, G. (2017). Retirement blues. Journal of Health Economics, 54, 66-78. https://doi.org/10.1016/J.JHEALECO.2017. 03.007

Henkens, K., Van Dalen, H. P., Ekerdt, D. J., Hershey, D. A., Hyde, M., Radl, J., van Solinge, H., Wang, M., \& Zacher, H. (2018). What We Need to Know about Retirement: Pressing Issues for the Coming Decade. The Gerontologist, 58(5), 805-812. https:// doi.org/10.1093/geront/gnx095

Henning, G., Lindwall, M., \& Johansson, B. (2016). Continuity in wellbeing in the transition to retirement. GeroPsych: The Journal of Gerontopsychology and Geriatric Psychiatry, 29(4), 225-237. https://doi.org/10.1024/1662-9647/a000155

Holmes, R. M., Jr., Bromiley, P., Devers, C. E., Holcomb, T. R., \& McGuire, J. B. (2011). Management theory applications of prospect theory: Accomplishments, challenges, and opportunities. Journal of Management, 37(4), 1069-1107. https://doi.org/10. $1177 / 0149206310394863$

Iyer, A., Jetten, J., Tsivrikos, D., Postmes, T., \& Haslam, S. A. (2009). The more (and the more compatible) the merrier: Multiple group memberships and identity compatibility as predictors of adjustment after life transitions. British Journal of Social Psychology, 48(4), 707-733. https://doi.org/10.1348/014466608X397628

James, W. (1890). The principles of psychology (Vols. 1 \& 2). New York Holt. https://doi.org/10.1037/11059-000

Jetten, J., Branscombe, N. R., Haslam, S. A., Haslam, C., Cruwys, T., Jones, J. M., Cui, L., Dingle, G., Liu, J., Murphy, S., Thai, S., Walter, Z., Zhang, A. (2015). Having a lot of a good thing: Multiple important group memberships as a source of self-esteem. PLoS ONE, 10(5). https://doi.org/10.1371/journal.pone.0124609

Jones, D. A., \& McIntosh, B. R. (2010). Organizational and occupational commitment in relation to bridge employment and retirement intentions. Journal of Vocational Behavior, 77(2), 290-303. https://doi.org/10.1016/j.jvb.2010.04.004

Kahneman, D., \& Tversky, A. (1984). Choices, values, and frames. American Psychologist, 39(4), 341-350. https://doi.org/10.1037/ 0003-066X.39.4.341

Kanfer, R., Beier, M. E., \& Ackerman, P. L. (2013). Goals and motivation related to work in later adulthood: An organizing framework. European Journal of Work and Organizational Psychology, 22(3), 253-264. https://doi.org/10.1080/1359432X.2012.734298

Katz, I. M., Rudolph, C. W., \& Zacher, H. (2019). Age and career commitment: Meta-analytic tests of competing linear versus curvilinear relationships. Journal of Vocational Behavior, 112, 396-416. https://doi.org/10.1016/j.jvb.2019.03.001

Kees, J., Berry, C., Burton, S., \& Sheehan, K. (2017). An analysis of data quality: Professional panels, student subject pools, and Amazon's Mechanical Turk. Journal of Advertising, 46(1), 141-155. https://doi.org/10.1080/00913367.2016.1269304

Keith, M. G., Tay, L., \& Harms, P. D. (2017). Systems perspective of amazon mechanical turk for organizational research: Review and recommendations. Frontiers in Psychology. https://doi.org/10.3389/ fpsyg.2017.01359

Kim, J. E., \& Moen, P. (2002). Retirement transitions, gender, and psychological well-being: A life-course, ecological model. Journals of Gerontology - Series B Psychological Sciences and Social Sciences, 57(3), P212-P222. https://doi.org/10.1093/geronb/57.3.P212

Kubicek, B., Korunka, C., Raymo, J. M., \& Hoonakker, P. (2011). Psychological well-being in retirement: The effects of personal and gendered contextual resources. Journal of Occupational Health Psychology, 16(2), 230-246. https://doi.org/10.1037/a0022334 
Leandro-França, C., van Solinge, H., Henkens, K., \& Murta, S. G. (2016). Effects of three types of retirement preparation program: A qualitative study of civil servants in Brazil. Educational Gerontology, 42(6), 388-400. https://doi.org/10.1080/03601277.2016.1139969

Levin, I. P., Schneider, S. L., \& Gaeth, G. J. (1998). All frames are not created equal: A typology and critical analysis of framing effects. Organizational Behavior and Human Decision Processes, 76(2), 149-188. https://doi.org/10.1006/obhd.1998.2804

Light, A. E., \& Visser, P. S. (2013). The Ins and Outs of the Self: Contrasting Role Exits and Role Entries as Predictors of Self-concept Clarity. Self and Identity, 12(3), 291-306. https://doi.org/10.1080/ 15298868.2012.667914

Lodi-Smith, J., \& Roberts, B. W. (2010). Getting to know me: Social role experiences and age differences in self-concept clarity during adulthood. Journal of Personality, 78(5), 1383-1410. https://doi.org/10. 1111/j.1467-6494.2010.00655.x

Lodi-Smith, J., Spain, S. M., Cologgi, K., \& Roberts, B. W. (2017). Development of identity clarity and content in adulthood. Journal of Personality and Social Psychology, 112(5), 755-768. https://doi. org/10.1037/pspp0000091

Markus, H., \& Wurf, E. (1987). The dynamic self-concept: A social psychological perspective. Annual Review of Psychology, 38(1), 299-337. https://doi.org/10.1146/annurev.ps.38.020187.001503

Marsh, H. W., Pekrun, R., Parker, P. D., Murayama, K., Guo, J., Dicke, T., \& Arens, A. K. (2019). The murky distinction between selfconcept and self-efficacy: Beware of lurking jingle-jangle fallacies. Journal of Educational Psychology, 111(2), 331-353. https://doi. org/10.1037/edu0000281

Mather, M., \& Carstensen, L. L. (2005). Aging and motivated cognition: The positivity effect in attention and memory. Trends in Cognitive Sciences. https://doi.org/10.1016/j.tics.2005.08.005

Mattingly, B. A., \& Lewandowski, G. W. (2013). The power of one: Benefits of individual self-expansion. Journal of Positive Psychology, 8(1), 12-22. https://doi.org/10.1080/17439760.2012.746999

Mattingly, B. A., \& Lewandowski, G. W. (2014). Expanding the Self Brick by Brick: Nonrelational Self-Expansion and Self-Concept Size. Social Psychological and Personality Science, 5(4), 484-490. https://doi.org/10.1177/1948550613503886

McIntyre, K. P., Mattingly, B. A., Lewandowski, G. W., \& Simpson, A. (2014). Workplace Self-Expansion: Implications for Job Satisfaction, Commitment, Self-Concept Clarity, and Self-Esteem Among the Employed and Unemployed. Basic and Applied Social Psychology, 36(1), 59-69. https://doi.org/10.1080/01973533.2013.856788

Mitchell, T. R., Thompson, L., Peterson, E., \& Cronk, R. (1997). Temporal Adjustments in the Evaluation of Events: The "Rosy View." Journal of Experimental Social Psychology, 33(4), 421-448. https:// doi.org/10.1006/jesp.1997.1333

Ng, T. W. H., \& Feldman, D. C. (2010). The relationships of age with job attitudes: A meta-analysis. Personnel Psychology, 63(3), 677718. https://doi.org/10.1111/j.1744-6570.2010.01184.x

Oyserman, D., Elmore, K., \& Smith, G. (2012). Self, self-concept, and identity. In M. R. Leary \& J. P. Tangney (Eds.), Handbook of self and identity (pp. 69-104). The Guilford Press.

Pak, K., Kooij, D. T., De Lange, A. H., Van den Heuvel, S., \& Van Veldhoven, M. J. (2021). The influence of human resource practices on perceived work ability and the preferred retirement age: A latent growth modelling approach. Human Resource Management Journal, 31(1), 311-325.https://doi.org/10.1111/1748-8583.12304

Reiff, J. S., Hershfield, H. E., \& Quoidbach, J. (2020). Identity Over Time: Perceived Similarity Between Selves Predicts Well-Being 10 Years Later. Social Psychological and Personality Science, 11(2), 160-167. https://doi.org/10.1177/1948550619843931

Richardson, V., \& Kilty, K. M. (2005). Adjustment to Retirement: Continuity vs. Discontinuity. The International Journal of Aging and
Human Development, 33(2), 151-169. https://doi.org/10.2190/ 6rpt-u8gn-vucv-p0tu

Rosenberg, M. (1965). Society and the adolescent self-image. Princeton University Press. https://doi.org/10.1515/9781400876136

Seongsu, K., \& Feldman, D. C. (2000). Working in retirement: The antecedents of bridge employment and its consequences for quality of life in retirement. Academy of Management Journal, 43(6), 1195-1210. https://doi.org/10.5465/1556345

Shapiro, D. N., Chandler, J., \& Mueller, P. A. (2013). Using mechanical turk to study clinical populations. Clinical Psychological Science, 1(2), 213-220. https://doi.org/10.1177/2167702612469015

Slotter, E. B., Gardner, W. L., \& Finkel, E. J. (2010). Who am I without you? The influence of romantic breakup on the self-concept. Personality and Social Psychology Bulletin, 36(2), 147-160. https://doi. org/10.1177/0146167209352250

Steffens, N. K., Jetten, J., Haslam, C., Cruwys, T., \& Haslam, S. A. (2016). Multiple Social Identities Enhance Health Post-Retirement Because They Are a Basis for Giving Social Support. Frontiers in Psychology, 7, 1519. https://doi.org/10.3389/fpsyg.2016.01519

Tajfel, H., \& Turner, J. (2001). An integrative theory of intergroup conflict. In M. A. Hogg \& D. Abrams (Eds.), Key readings in social psychology Intergroup relations: Essential readings (pp. 94-109). Psychology Press.

Taylor, M. A., \& Shore, L. M. (1995). Predictors of planned retirement age: An application of Beehr's model. Psychology and Aging, 10(1), 76-83. https://doi.org/10.1037/0882-7974.10.1.76

Truxillo, D. M., Cadiz, D. M., \& Hammer, L. B. (2015). Supporting the Aging Workforce: A Review and Recommendations for Workplace Intervention Research. Annual Review of Organizational Psychology and Organizational Behavior, 2(1), 351-381. https://doi.org/10. 1146/annurev-orgpsych-032414-111435

van Solinge, H., \& Henkens, K. (2007). Involuntary retirement: The role of restrictive circumstances, timing, and social embeddedness. The Journals of Gerontology Series b: Psychological Sciences and Social Sciences, 62(5), S295-S303. https://doi.org/10.1093/geronb/ 62.5.S295

Wang, M. (2007). Profiling retirees in the retirement transition and adjustment process: Examining the longitudinal change patterns of retirees' psychological well-being. Journal of Applied Psychology, 92(2), 455-474. https://doi.org/10.1037/0021-9010.92.2.455

Wang, M., \& Shi, J. (2014). Psychological research on retirement. Annual Review of Psychology, 65, 209-233. https://doi.org/10.1146/annur ev-psych-010213-115131

Williamson, V. (2016). On the ethics of crowdsourced research. PS: Political Science \& Politics, 49(1), 77-81. https://doi.org/10.1017/ S104909651500116X

Wilson, T. D., \& Gilbert, D. T. (2005). Affective forecasting: Knowing what to want. Current Directions in Psychological Science, 14(3), 131-134. https://doi.org/10.1111/j.0963-7214.2005.00355.x

Zhan, Y., Wang, M., \& Yao, X. (2013). Domain specific effects of commitment on bridge employment decisions: The moderating role of economic stress. European Journal of Work and Organizational Psychology, 22(3), 362-375. https://doi.org/10.1080/1359432X. 2012.762763

Zittoun, T., Duveen, G., Gillespie, A., Ivinson, G., \& Psaltis, C. (2003). The Use of Symbolic Resources in Developmental Transitions. Culture and Psychology, 9(4), 415-448. https://doi.org/10.1177/13540 $67 \mathrm{X} 03940$

Publisher's Note Springer Nature remains neutral with regard to jurisdictional claims in published maps and institutional affiliations. 